\title{
Bir edebî tenkit örneği olarak Selim İleri’nin “Seni Çok Özledim” adlı eseri
}

\section{Funda ÇAPAN ÖZDEMİR}

\begin{abstract}
APA: Çapan Özdemir, F. (2020). Bir edebî tenkit örneği olarak Selim İleri’nin "Seni Çok Özledim" adlı eseri. RumeliDE Dil ve Edebiyat Araştırmaları Dergisi, (Ö7), 264-271. DOI: 10.29000/rumelide.808692.
\end{abstract}

\section{Öz}

Daha çok roman, öykü, deneme ve anı türünde kaleme aldığı eserleriyle tanınan Selim İleri’nin "Seni Çok Özledim" adlı kitabında, edebî eserleri titizlikle değerlendirmesi dikkate değerdir. Bu tür yazılarında Selim İleri, edebî eserleri, yazarları, edebiyat-sanat çevrelerini, klâsik eserlerin kendisinde bıraktığı tesirleri, hayat-edebiyat ilişkisi bağlamında ele alır. Hayattaki her güzel şey gibi edebî eserler de insan üzerinde tesirler bırakırlar; edebiyat, hayata dair insana dair değerlerin bir bakıma yansımasıdır. Bu bağlamda, Selim İleri gibi zengin kültür birikimi ve yazar hassasiyetiyle edebiyat meselelerini gündeme getiren yazarların edebî tenkit alanındaki yazıları ayrı bir önem taşır. Bu bakımdan çalışmamızda, Selim İleri’nin bir yazar olarak, edebî eserleri nasıl bir bakış açısıyla tenkit ettiğine ve edebî metinlerde hangi hususiyetlere önem verdiğine dair bilgilerin yanı sıra eser-yazar-okur arasındaki sanatsal bağ kurma çabaları üzerinde durduk.

Anahtar kelimeler: Edebiyat, eser, okur, yazar, eleştiri

\section{In Selim Ileri’s work “Seni Çok Özledim” language and literature views}

\begin{abstract}
In the book "I Miss You Very Much" by Selim İleri, who is known for his works mostly in the genre of novels, stories, essays and memoirs, it is noteworthy that he meticulously evaluated literary works. In this kind of writings, Selim İleri discusses literary works, writers, literature-art circles, the effects of classical works on him in the context of life-literature relationship. Literary works, like all good things in life, have an impact on people; In a sense, literature is a reflection of human values about life. In this context, the writings of writers such as Selim Illeri, who bring up literary issues with his rich cultural background and author sensitivity, are of particular importance. In this respect, in our study, we focused on the information about Selim İleri's criticism of literary works as a writer and the characteristics he attaches importance to in literary texts, as well as his efforts to establish an artistic connection between the work-writer-reader.
\end{abstract}

Keywords: Literature, work, reader, writer, criticism

\section{Giriş}

Eleştiri, intikad, kritik gibi edebiyat terimlerinin yerine kullanılabilen tenkit, edebiyat eserlerini değerlendirmek, incelemek, yargılamak, tanıtmak, bu eserlerin üstün veya eksik yanlarını ortaya çıkarmak amacıyla kaleme alınan yazılardır. Dil ve edebiyata dair tenkit yazılarında, tenkitçinin hassasiyeti, bilgi, kültür ve deneyimi, hedef kitlesi, edebiyatın gelişim seyrini etkileme gibi özellikler

Dr. Öğr. Üyesi, Yozgat Bozok Üniversitesi, Fen Edebiyat Fakültesi, Türk Dili ve Edebiyatı Bölümü (Yozgat, Türkiye), funda.capan.ozdemir@bozok.edu.tr, ORCID ID: 00oo-0002-3950-4842 [Makale kaylt tarihi: 21.08.2020-kabul tarihi: 20.10.2020; DOI: 10.29000/rumelide.808692] 
önem kazanır. Bu bakımdan Tahsin Yücel’in eleştiriyi "bir okuma deneyiminin aktarılması" olarak yorumlaması dikkate değerdir (Karataş, 2004: 139).

İngiliz edebiyatında eleştiri; sanat eserlerini ve tekniklerini açıklayıp değerlendiren mantıklı ve sistematik, kamuoyuna karşı sorumlu bir inceleme olarak anlaşılırken; Alman edebiyatında eleştirmenin hedefi, okur kitlesini etkilemek ve edebiyat hayatının gelişimini aynı zamanda stratejik bir şekilde yönlendirmektir (Aytaç, 2016: 83). Gürsel Aytaç’a göre, edebiyat eleştirisinin tarihî gelişiminde üç ana nokta arasında durmadan yer değiştirmesi, dikkati çeker: Bunlardan birincisi, kamuoyunun mantık dünyasına, ikincisi sanata (ve estetik gelişime) ve üçüncüsü de halkın ilgi alanlarına yönelmesi; onun hoşça vakit geçirme, iman tazeleme ve siyasî yapılanma ihtiyacını tazelemesidir (Aytaç, 2016: 85).

Eleştirinin birinci temel biçimi, kuralcı-akılcı ise, ikinci temel biçimi ise edebiyatın bağımsızlığı ilkesinden kaynağını alan tarzdır ve Alman edebiyatında "deha estetiği” olarak adlandırılır ki bu anlayış, sanatın en iyi eleştiricisi yine sanattır anlayışını benimseyen bu eleştirinin kendisi de "üretici" ve "edebî” olma özelliğine sahiptir. Yazar ve şairlerin başkalarının edebî eserleri üzerine yazdığı eleştiriler bu kapsama girer (Aytaç, 2016: 86). Selim İleri’nin "Seni Çok Özledim" yapitında da bu türden bir sanat seçkinciliğini esas alan, çağın ve okurların eğilimlerini fark eden bir sanatsal duyarllık söz konusudur.

Selim İleri’nin "Seni Çok Özledim" adlı eseri, birinci basımı 1986 tarihinde İstanbul'da yayımlanan, yazarın 1978-1986 yılları arasında kaleme aldığı bilhassa klâsik eserlere dair tenkidî görüşlerini kapsar. Bu eserinde Selim İleri, yazarları ve edebî eserleri, kendisinde bıraktığı tesirler, edebiyat ve sanat çevrelerinden edindiği izlenimler ve hayat-edebiyat ilişkisi bağlamında değerlendirir. $\mathrm{Bu}$ bakımdan sanatkâr hassasiyeti, zengin kültür birikimiyle edebiyat meselelerini gündeme getiren Selim İleri’nin edebî tenkit alanındaki yazıları ayrı bir önem taşır. Çalışmamızda, Selim İleri’nin bir yazar olarak, edebî eserleri nasıl bir bakış açısıyla tenkit ettiğine ve edebî metinlerde hangi hususiyetlere önem verdiğine, üstün ve eksik gördüğü özelliklere dair bilgilerin yanı sıra eser-yazar-okur arasındaki sanatsal bağ kurma çabalarını değerlendirdik.

\section{Selim İleri ve yazarlar-eserleri}

Selim İleri'de tenkit fikrinin gelişiminde; onun sanata ve edebiyata olan düşkünlüğünün yanı sıra okuduklarının, dinlediklerinin ve araştırdıklarının etkisi altında kalan; araştırmacı yönü kuvvetli bir yazar oluşu mühimdir. Selim İleri'nin "Seni Çok Özledim” adlı kitabında, Oğuz Atay’ın yaşamının son dönemlerinde kaleme aldığı bir metin için “Bu, Oğuz Atay'ın bize son armağanıydı. (İleri, 1986: 33)” cümlesi, İleri’nin yazarlara ait eserleri ne denli içselleştirdiğinin; onları kendi yazarlık serüveni ve Türk edebiyatı için birer kazanım olarak düşündüğünün açık bir ifadesidir.

Selim İleri, çocukluğundan itibaren okumayı alışkanlık haline getiren; okuduklarıyla hayatı arasında etkili bir bağ kurabilen bir yazardır. Okuduğu kitaplar, onda kimi zaman mutluluk; kimi zamansa hüzün duygusu bırakır. Kitaplar arasında seçici oluşu ve beğenileri, yazarda çok küçük yaşlardan itibaren gelişmiştir:

Çocukken çok severek, defalarca okuduğum bir kitabın adı Çocuklara Altın Masallar'dı. Öyle sanıyorum ki hemen hepsi Fransız edebiyatından seçilip kısaltılarak dilimize çevrilmiş bu masallar, bende derin bir mutluluk bırakmıştı. 
Çocukluğun kitapları bir yerde yitiyor. Çocuklara Altın Masallar'ı yıllar sonra Sahaflar'da buldum; şimdi yaşlılık günlerim için saklıyorum (İleri, 2001: 7)."

Selim İleri, bilhassa klâsik eserler üzerinde önemle durur. Başta Ahmet Midhat Efendi olmak üzere, ilk romancılarımızın Türk edebiyatının gelişim süreci için büyük çaba harcadıklarını düşünür. İlk romancılarımız, romana giden yolda geleneksel edebiyattan, masallardan, halk hikâyelerinden, tarihî metinlerden, Divan şiirinin anlatıma dayalı bazı özelliklerinden yararlanmışlardır. Selim İleri, bu yazarlara saygı duyar (İleri, 2001: 8). Edebî eserler üzerinde yazdığı tenkit yazılarının amaçlarından birisi de bu gibi eserleri gündeme getirmektir (İleri, 2001: 9).

Selim İleri, her yazarın yazma serüvenindeki amacının sadece "beğenilmek" olmadığını düşünür. İleri'ye göre, yazarlar her şeyden evvel yazdıklarının "okunması" için onları kaleme almışlardır. İleri, bilhassa beğendiği, Türk edebiyatının ve Türk kültürünün eşsiz birer hazinesi olarak gördüğü eserleri, gündeme getirerek onları, "tanıtmak" ve "yaşatmak" gayesindedir. Selim İleri’ye göre, yüz yll önce yazılmış eserler ile okur arasında içsel bir yakınlık, bir bağ söz konusudur: "Yüz yll önce yazılmış bir romanın kişileri, gönlünüzü dinleyin, kimileyin çevremizdekilerden çok daha yakındır bize. İlerideki sayfalarda şöyle bir görünüp, ama izler bırakarak kaybolacak Bihter'ler, Suad'lar, Hakkı Celis'ler, Mümtaz'lar bende hâlâ yaşıyor. Günler var ki, onlarla buluşuyor, onlarla görüşüyor, onlarla söyleşiyorum. Kalbim onlara ne çok şey borçlu! (İleri, 2001: 10)”

Selim İleri, klâsik yazarların yapıtları üzerinde durmayı bir görev olarak düşünür (İleri, 1986: 148). İleri, kitapların meydana geliş koşullarını göz önünde bulundurmayarak yapılan değerlendirmelere, eksik yorumlara ve haksızlıklara esef eder. Eleştirmenlerin bu gibi hatalarından duyduğu rahatsızlık, Selim İleri'yi edebiyat meselelerini gündeme getiren tenkit yazıları yazmaya mecbur bırakmıştır; çünkü her şeyden evvel edebî eserleri yazma serüvenini iyi bilen Selim İleri, eserler üzerine yaptığı yorumlarda, onların yazılış dönemlerine ait şartları göz önünde bulundurur: "Bir yazarı ve yapıtını kavramak, alımlamak, kavrayıp alımladıklarımızı da yazıya geçirerek başkalarına açıklamak, her şeyden önce yazarın ve yapıtının meydana geliş koşullarıyla çok yakından ilintilidir. Namık Kemal'in İntibah'ına, Sezai'nin Sergüzeşt'ine, acemi, zayıf roman diyebilmek; o dönemlerde bu romanları aşmış yetkin romanlarımız da vardı... demekle eşanlamlıdır. Herkes biliyor ki yoktu. Sonra düşünün, Namık Kemal romanının adını bile seçmekle özgür değildi. İşte bu tarz sorunların roman yazmamış eleştirmenlerimizce saptanamadığını gördüğümden, düşüncelerimi yazmaya çalışıyorum (İleri, 1986: 148).”

Selim İleri’nin bilhassa roman sanatında gördüğü eksikliklerden biri, eserlerde "içtenlik" fikrinin olmayışıdır. İleri'ye göre, Türk romanı, insanı, genellikle psikoloji dışı düzlemlerde aramış, psikolojisinin dışında yansıtmayı ön görmüştür. Buna göre, hem iyi hem kötü olabilen, yaşamın akışında değişen, toplumsal koşullarla nitelik kazanan ya da kaybeden roman kişileri de tek boyutlu olarak anlatılır. Selim İleri, roman kişilerinin tek boyutlu anlatılmasına, içsel dünyalarına layıkıyla nüfuz edilememesine esef eder: "Çünkü bize hiçbir zaman gizlerini söylemezler. İç dökmezler, acı çektiklerinde bile kayıtsız gibidirler... Bu kapalı bir toplum oluşumuzdan kaynaklanmaktadır. Bizi oluşturan, toplumumuza töresini hazırlayan, beş aşağı beş yukarı kapalı iktisattır. Burada 'içtenlik' diye bir sorun da zaten söz konusu edilemeyecektir (İleri, 1986: 53). 


\section{Tanzimat devri}

Selim İleri, “Samipaşazade Sezai’nin Değeri” başlıklı yazısında, Rûşen Eşref'in Diyorlar ki adlı eserine dikkati çeker. Bu eserde, Samipaşazade Sezai "yer yer çok ince bir alaycılığa" ve "kavrayışsızca bir söyleme” kurban edilmiştir (İleri, 1986: 124). Selim İleri, Ruşen Eşref'in bütün eski edebiyatçılarımıza, kendilerine göre yenilikler için savaşmış sanatçılarımıza haksızlık ettiğini ifade eder. Selim İleri, Samipaşazade Sezai'yi, yazarlık yaşamı boyunca, romantizmle gerçekçilik, gerçekçilikle ihtilalciliğe yatkın bir kalem kavgacılığı içinde düşünür. Selim İleri, Samipaşazade Sezai'nin yenilik edebiyatımızın ilk büyük sanatçı yazarı olarak yorumlarken Tanzimat yazarları arasında mukayese yapar: "Ahmet Midhat Efendi'nin yaygınlaşma çabasına karşllı, o, Namı Kemal'in iz'inde yürümüş, ama metinlerinde yazınsal gerçeklikler, inandırıcılıklar açısından daha incelikli olabilmiştir. İntibah'la Sergüzeşt yan yana okunduğunda, Sezai'nin bir edebiyat gerçekliği yaratılmak için nasıl mücadele ettiğini kavrarız. Sergüzeşt'te duyumsayış öndedir; düşüncenin kuru kuruya aktarılması yerine, romantizmden esintilerle metin bütünlenir. Namık Kemal'de yer yer karşımıza çıkan -handiysemeddah ağzı, Sezai'de tamamıyla susturulmuştur (İleri, 1986: 126).”

Selim İleri, Samipaşazade Sezai’nin Sergüzeşt adlı romanında, çeşitli toplumsal katmanları birarada değerlendirmesi ve eleştirmesi, kısa öykülerinde yazınsal gerçekliğin daima ölçüp biçmesi, siyasal yazılarında bir sağduyu elden bırakmayışı bakımından Sezai'yi edebiyatımızın saygın bir yazarı olarak kabul eder. Selim İleri, Samipaşazade Sezai hakkında yorum yaparken, edebiyatımızın bir sorununu da gündeme getirir. Selim İleri'ye göre, memleketin baskıyla donatılmış olması, sanatla, uğraşmak isteyen kişiyi o kadar çok durdurmuş, kösteklemiştir ki bu sebeple Sezai de sonunda yazmaktan ve bilhassa "yaratımsal verim"den caymıştır (İleri, 1986: 132). Buna göre Selim İleri, memleketteki baskı ortamının sanatın ve sanatçının önünde, sanatsal üretkenlik bağlamında bir engel olarak düşünür.

Selim İleri'ye göre ilk romancılarımız, eserlerinde acıma duygusunun ötesine geçememişlerdir; sadece kapalı toplum düzeninin çelişkilerini "bilinçsizce" saptayabilmişlerdir (İleri, 1986: 147). Selim İleri'ye göre Ahmet Midhat Efendi, insan acılarını hiçbir zaman derinlemesine hissedemeyen bir yazardır. İleri'ye göre, kimi eserlerinde toplumsal farklardan ya da bireysel sorunlardan kaynaklanmış insan acılarını yansıtır; fakat bu acılara ya çok yalınkat çözümler bulur, ya da gelgeç izlenimlerle yetinir. Bu bakımdan Selim İleri, Sezai’nin bir duyarlılı̆̆ı sonuna kadar götürmesini, eserlerinde iç güzelliğe önem vermesini yüceltir: "Sezai toplumumuzda hemen hiç kavranamayacak olan iç güzelliğine 'Pandomima'da da yer verir... Samipaşazade Sezai, edebiyatında hep acıma duygusunu öne çlkararak, yazınsal bildirisini bu yönde odaklandıracaktır (İleri, 1986: 128).”

Ahmet Midhat Efendi’nin takipçisi olan Hüseyin Rahmi Gürpınar, Selim İleri’ye göre, Türk toplumunun "asıl" genel görünümü saptayabilmiş bir romancıdır. Selim İleri, Hüseyin Rahmi’nin edebiyat tarihimiz açısından gerçek anlamıyla incelenmesi gerektiğine inanır (İleri, 1986: 148). Selim İleri'ye göre Hüseyin Rahmi Gürpınar, Nietzsche'yi yerlileştiren ve yaşamı biraz da bu filozofun gözünden görmek isteyen, bize özgü yaşamanın en doğal biçimde ifade ediliş olanaklarını arayan, toplumsal hayatımızı çok geniş bir perspektiften irdeleyen, eserlerinde olağanüstü canlı sahnelere yer veren ve bu gibi özellikleriyle Türk romanı açısından benzersiz kalmış bir yazardır (İleri, 1986: 149$150)$.

Selim İleri, Hüseyin Rahmi Gürpınar'ın eserlerini yorumlarken, edebiyatımızda denetimler, özdenetimler, sanatın özgürlüğü ve bağımsızlığı meselelerine dikkati çeker. Selim İleriłye göre Hüseyin Rahmi Gürpınar’n yazarlığında “denetim”, olumsuz etkiler bırakmıştır. Selim İleri, Hüseyin 
Rahmi’nin “Ben Deli miyim?” adlı romanı dava edildiğinde, Hüseyin Rahmi’nin savunmasını nakleder: "Roman, ahlakın aynasıdır; onun objektifi, gördüğü manzarayı alır. Müddeiumumî istiyor mu ki roman gördüğü çirkinlikleri, yaraların kokusunu değiştirsin, riya, cehl ve taassuba âlet olarak hakikati diri diri gömdürmeğe razı olsun?.. Fakat, o zaman hikâyenin, sanatın lüzumu kalır mı? Hayır efendim, hayır! Hiçbir hükümet, hiçbir memleket; sanatı asaletinden soyup, yalancı şahitlik derecesine indiremez. (İleri, 1986: 151).” Selim İleri, Hüseyin Rahmi’nin bu görüşlerine tamamen hak verir. Bu bakımdan, Hüseyin Rahmi'yi günümüz romancısından çok daha cesur görür. Selim İleri, Hüseyin Rahmi’nin bazı kitaplarına yazdığı önsözlerde denetleyici yasaların sanat eseri idrak edilmeden hazırlandığına işaret eder ve bu sorunun hâlâ güncelliğini koruduğunu ifade eder (İleri, 1986: 151). Bu bağlamda Selim İleri, sanat eseri açısından "müstehcen yayınlar" sorununu, Hüseyin Rahmi'den günümüze kadar hiç açılım kazanamamış bir darlığın, dargörüşlülüğün uzantısı olarak yorumlar (İleri, 1986: 195).

\section{Servet-i Fünûn devri}

Selim İleri, Servet-i Fünun dönemi yazarlarından Halit Ziya Uşaklıgil’in Aşk-ı Memnu adlı romanını, aradan geçen senelere rağmen "aşllamamış" bir eser olarak yorumlar. İleri'ye göre, Halit Ziya, döneminin edebiyat anlayışını, roman kavrayışını adeta bir devrimle değiştirmeyi, "kendi bildiğini okumayı" göze almıştır (İleri, 1986: 14). İleri’ye göre, meddah hikayesinin bütün izleri Aşk-ı Memnu ile birlikte silinmiştir. Bu bağlamda Selim İleri, Tanzimat dönemi romancıları ile Halit Ziya'yı mukayese eder: Yazarlık yaşamı boyunca duygularının bilmecesini çözmüş kişileri yazmak isteyen Halit Ziya, bir nevi geleneğe ve ahlaki kaygılara tutsak düşer. Buna karşılı, Tanzimat romancıları, bireyin duygularında "muamma" aramak yerine kişilerini kartonlaştırmak için çaba harcamışlardır (İleri, 1986: 14). Sergüzeşt romanında ise, duygularının bilmecesini, romanda değil, roman öncesinde ve sonrasında çözmek, denenmiştir (İleri, 1986: 14).

Selim İleri, Aşk-ı Memnu'nun baştan sona ruhsal çözümleme üzerine kurulu olduğunu ifade eder ve roman sanatında psikolojinin ağırlık kazandığı iç görünüme ayrı bir önem verir (İleri, 1986: 16). İleri'ye göre, sanatta kural koymak ne kadar yanlışsa, sadece dış görünümle yetinerek roman yazmak da bir o kadar yanlıştır: "İç düşünceler, bireysel izlenimler, duygulanımlar... Dış görünümle yetinerek roman yazılabilir mi? Sanatta kural koymak kadar yanlış ne olabilir? Yazılır tabiî, yazılmıştır da. Gelgelelim ben iç görünüm tutkunuyum. Bir roman ille de iç görünümlerden söz açmalı.” (İleri, 1986: 16).

\section{Meşrutiyet devri}

Selim İleri, Halide Edib Adıvar'ın Handan adlı romanını diğer tenkit yazılarındaki gibi bilhassa psikolojik yönden tahlil eder. Handan'ın bütün duygulanışlarını yorumlayan Selim İleri’ye göre Handan, gerçek duygularını yaşamamış insandır. En sonunda geçmişindeki erkekleri hep birarada hisseden Handan, bilinç dışı özgürlüğünün etkisiyle en sonunda Refik Cemal'e âşık olur. Refik Cemal de tekdüze yaşamında parçalanmış bir ruh haliyle, Handan'ın ihtirasını yanıtlar (İleri, 1986: 103).

\section{Cumhuriyet dönemi}

Selim İleri'ye göre, Abdülhak Şinasi Hisar eserlerinde İstanbul'a ve özellikle Boğaziçi’ne bir romans duyarlılı̆̆ıla yaklaşan ve özgün anlatıma sahip bir yazardır. Selim İleri’ye göre, Abdülhak Şinasi, geçmişi bile kendi gerçeklikleri içinde hatırlamak istemeyen bir rüya yalnızlığının insanıdır (İleri, 
1986: 133). Selim İleri, Abdülhak Şinasi'deki bu geçmiş zaman fikrinden bahsederken kendi fikirlerini söz konusu eder. İleri’ye göre, geçmişe sığınmak tek imkândır; çünkü günün siyasal yazarından, bu yazarın kaypaklığından, her gün ayrı bir dille, sık sık ağız değiştirerek konuşmasından tiksinti duyulduğunda; güne ilişkin somut gerçekliği değiştirmek, herkesin her an gördüğünü, ölçüp tartabileceğini başkalaştırmak olanaksızlaşır. Bu sebeple, yaşanmamış bir maziyi yazmanın çok daha elverişli olduğuna inanan Selim İleri, hayatı bu yaşanmamış mazi içerisinde dilediğimiz kadar bezeyebileceğimizi düşünür (İleri, 1986: 136).

Selim İleri, Abdülhak Şinasi Hisar’ın semtlerimizin hepsini başlı başına bir uygarlık olarak görüşüne dikkati çeker: "Bu özel medeniyeti bir yandan tabiat sevgisi besler, bir yandan musiki iptilası, hepsinden de çok mazinin mahremiyetleriyle dolup taşan İstanbul, Boğaziçi töresi. O, uygarlığın ve törenin daima olumlu taraflarını görür. Eski hayatımızın kozmopolit ögelerini birleştirici sayar; imparatorluğun bünyesindeki farklı milliyetleri daima kucaklar (İleri, 1986: 137).” Selim İleri’ye göre, yozlaşmamış alaturka duyarlılığı, Abdülhak Şinasi ölçüsünde düzyazıya yedirebilmiş bir başka yazarımız yoktur. İleri, Abdülhak Şinasi’nin seçtiği eski ve yeni sözcüklerde bile bu duyarlılığı gösteren özel bir sözlüğü olduğuna inanır (İleri, 1986: 138).

Selim İleri, edebiyatımızın büyük yazarı olarak düşündügü Tanpınar'ın eserlerinde ileri sürdüğü konuların, sorunların, düşüncelerin ve önerilerin üzerinde layıkıla durulmamasına esef eder. Buna karşılık İleri, gerçek bir eleştirmenin bu verilerden geniş çıkarımlar sağlayabileceği görüşündedir. İleri'ye göre, Tanpınar kültürel mirasın korunması amacıyla adeta bizlere bir an önce iletmek ister: "Tanpınar, sanki gördüğ ̈̈, ayrımsadığı, irdelediği konuları, sorunları, olguları, bize bir an önce iletmek istiyor; kültürel mirasın hızla harcandığını saptamanın telaşı belki de... (İleri, 1986: 45)." Ayrıca, Tanpınar'ın Huzur adlı eseri de yazarın yaşamı boyunca hangi "yalnızlık" tecrübelerinden geçtiğinin ve "büyük bir iç firtına”nın göstergesi olduğunu düşünür (İleri, 1986: 46).

Selim İleri'ye göre, Cumhuriyet devri şairlerinden Asaf Hâlet Çelebi, Türkiye yerine herhangi bir Avrupa ülkesinde yaşasaydı, özgün, düzeyli, düşündürücü, kimi zaman da popülist duyarlıklar içeren şiirleriyle okunurdu, tartışılırdı, eleştirilirdi. Halbuki, $H e$ 'de sızlatıcı bir içsel acıyı dile getiren şairin metafizik duyarlılığının okunmasına ve yazılmasına, dönemin aydın kesimi karşı çıkmıştır (İleri, 1986: 21). Selim İleri, Asaf Hâlet Çelebi'yi daha çok başka yazarların eserlerindeki metinler yoluyla değerlendirmeye çalışsa da bu metinlerin yazarı anlatmakta yetersiz kaldığını düşünür. Selim İleri, Kemal Sülker'in Anılara Yolculuk adlı eserinde Asaf Hâlet Çelebi’nin bir portresi için "Acaba gerçekten bu kadar mı Asaf Hâlet Çelebi? (İleri, 1986: 143).” sorusunu sorar. Selim İleri, Melih Cevdet Anday'ın kültür tarihimizin çarpıklıklarına olağanüstü açıklamalar katan anılarının yer aldığı Akan Zaman, Duran Zaman'da Asaf Hâlet Çelebi'nin özel hayatına dair bilgiler verdiğinden bahseder. Buna karşllık, İleri, kimi yeni yazarlarımızın Asaf Hâlet Çelebi'den söz açarken doğrudan doğruya onun eserlerine yönelmelerini sevindirici bulur (İleri, 1986: 144).

Selim İleri, Reşat Nuri Güntekin’i şüphesiz gerçekçiliği bütün yönsemeleriyle ve çatışmalarıyla görebilmiş bir yazar olarak değerlendirir. Selim İleri’ye göre, Reşat Nuri yapıtında "yarı çocuk, yarı yılan" kimlikleri daima çocuktan yana törpülemeyi gereksinmiştir (İleri, 1986: 209-210). Bu bakımdan Tanpınar, onda Halit Ziya'nın cesaretini bulamaz. Selim İleri, Reşat Nuri'nin eserlerinde bahsi geçen yılan kimliklerden kaçınmasını, kendi romancılığı açısından tutarlı bir davranış, üzerinde düşünülmüş bir seçim olarak yorumlar (İleri, 1986: 210). Selim İleri'ye göre, Reşat Nuri, bütün bir ülkede şefkate şiddetle ihtiyaç duyduğumuzu hissetmiştir ve işte bu "sezgi", ona "uçsuz bucaksız bir roman dünyası" 
sağlamıştır. Selim İleri’ye göre, tuhaf ve mucizemsi olan, bu tek taraflı bakış açısının, Reşat Nuri’nin yazınsal değerinden hiçbir şey eksiltmemesidir (İleri, 1986: 211).

Selim İleri, Behçet Necatil'in şiirlerini değerlendirirken onun yaşamıyla şiiri arasında bir bağ olduğunu ifade eder. Selim İleri, Necatigil'e, "alçakgönüllülüğün ta kendisi, duyguların çok ince kuyumcusu ya da sonsuz utanmanın simgesi” gibi özellikler atfeder. İleri, Necatigil'in şiirlerinde ve yaşamı boyunca hep bir eskinin terbiyesinden geçtiğini vurgular: "Yok, Necatigil, hiçbir zaman apartmana çıkmamıştır. O, şiiriyle, davranışıyla, şiir dışındaki edebî çalışmalarıyla hep eski... Çok eski bir sokağın terbiyesini, çelebiliğini, yücegönüllülüğünü, kadirbilirliğini yaşamıştır. O, orada çilesini yazmıştır (İleri, 1986: 33)."

Selim İleri, Oğuz Atay'ın kaleme aldığı edebiyat metinlerinin içeriğindeki gizli mizaha rağmen, bunların "hayat kadar acı veren metinler" olduğu görüşündedir. İleri’ye göre, Oğuz Atay bu dünyaya birbirinden anlamlı yapıtlar bırakmıştır. Atay’ı "güç bir yazar, önemli bir yazar ve yarının yazarı" olarak tanımlar. Selim İleri, okurların edebiyata ve sanata olan ilgisi arttıkça yani bir nevi okurların kültür düzeyleri de yükseldikçe, Oğuz Atay'ın kitaplarına olan ilginin de artacağını ve eserlerinin zevkle okunacağını ileri sürer (İleri, 1986: 35)

Selim İleri, hayatında Füruzan kadar kitap okuma tutkunu bir ikinci yazar tanımadığını ifade eder. İleri, kendisinin eski yıllardan farklı olarak, kitapları "bilgiç bir yazar tavrıyla, notlar alarak, eleştirel gözle, kimi zaman da teknik yardım umarak” okuduğunu dile getirir. Buna karşılık, Füruzan’ın yazarlığının belli başlı özelliklerinden biri olarak ondaki ruhi coşkunluğa dikkati çeker: "Gelgelelim Füruzan hep aşkla yaklaşır kitaplara. Kitap onun için başlıbaşına bir kutsallıktır. Mecidiyeköy'deki şirin, derli toplu evinin bütün duvarları kitaplığa dönüştürülmüştür. Bitmek bilmeyen bir coşkuyla hemen her yeni yayını izler. Yargıları nesneldir. Sözgelimi kendisini beğenmeyen yazarları övdüğü, hatta biraz fazlaca göklere çıkardığı olmuştur (İleri, 1986: 25).”

\section{Dünya edebiyatından yazarlar ve eserleri}

Selim İleri, okul sıralarından itibaren Tolstoy’u okuduğunu; fakat bir türlü özümseyemediğini ifade eder. İleri'nin okuma serüveninde Gustave Flaubert'in Gönül Eğitimi -Bir Delikanlının Romanı-, Madame Bovary adlı eserleri ile Tolstoy'un Anna Karenina ve Diriliş adlı yapıtlarının özel bir yeri vardır (İleri, 1986: 25). Selim İleri, Tolstoy'un Anna Karenina'dan bahsederken "romanda içtenlik" meselesine değinir. Bu bakımdan Selim İleri, Tolstoy’u ve Dostoyevski'yi mukayese eder: Tolstoy'un kurallara bağlılık arayışına karşılık, Dostoyevski bütün roman kişilerinde değişken ruh durumları saptar, kimsenin serüvenini yalınlaştırmaz; o da içtenlik sorununa geniş yer verir. İleri’ye göre, Dostoyevski'nin içtenlikten anladığı, insanın kendi iç karmaşasını gerekli yerde dışa vurmasıdır. İleri’ye göre Ecinniler yazarını, çă̆daş romana yaklaştıran işte bu tutumudur (İleri, 1986: 52).

\section{Sonuç}

Selim İleri, "Seni Çok Özledim” adlı eserindeki yazılarında kendine özgü bir eleştirel anlayış geliştirmiştir: 1. Yazarları ve eserleri bir sanatkâr hassasiyeti ve büyük bir titizlik ile yorumlarken kendi yazma sevinci ve yazma serüveninden hareket eder. 2. Başta Türk edebiyatına ve Türk kültürüne olmak üzere, kendisinin ve diğer yazarların yazma serüvenine katkıda bulunmayı amaç edinmiştir. Dolayısıyla, Selim İleri, eleştiriyi ciddiye alan bir yazardır. Selim İleri'nin "Her kitap, bir yürek açıştır (İleri, 1986: 160)." ifadesinden hareketle; yazarın kaleme aldığı her bir eleştiri yazısının da doğrudan 
doğruya okurlara seslenen, yazarları ve eserleri bir yürek açışı hassasiyetiyle, çekinmeden, açıkça değerlendiren metinler olduğunu söyleyebiliriz. 3. Selim İleri, eleştirel anlayışını geliştirirken, eserleri "yaşatmak" ve "tanıtmak" gayesinin yanı sıra "sorgulama" ilkesine riayet eden bir yazardır. 4. Roman kişilerinin bireysel sarsıntılarına, sevinçlerine, huzursuzluklarına, geniş anlamda ruhî çözümlemelere önem veren bir eleştiri yazarıdır. 5. Yorumlarında edebiyat tarihimizin temel bilgilerinden, yazarlar ve eserler arasında kurduğu bağlantılar yoluyla bir mukayese fikrinden hareket eder. 6 . Kendisinin de yazar oluşunun katkısıyla, edebiyat meselelerini farklı bakış açılarıyla ele alır. 7. Sanat eseri bağlamında "içtenlik" ve "müstehcen yayınlar sorunu" gibi meseleleri gündeme taşır. Bu bakımdan, yazarlar üzerinde uygulanan denetimlerin meydana getirdiği baskıları, sanatsal verimliliğin önünde büyük bir engel olarak düşünür.

\section{Kaynakça}

Aytaç, Gürsel ( 2016). Edebiyat Üzerine, Ankara: Hece

Çetişli, İsmail (2001). Batı Edebiyatında Edebî Akımlar, Ankara: Akçağ.

Enginün, İnci. (1991). Yeni Türk Araştırmaları, İstanbul: Dergâh.

Enginün, İnci. (2006). Cumhuriyet Dönemi Türk Edebiyatı, İstanbul: Dergâh.

İleri, Selim (2001). Türk Romanından Altın Sayfalar, İstanbul: Doğan Kitap.

İleri, Selim (1986). Seni Çok Özledim. İstanbul: Özgür.

Kaplan, Mehmet. (2001). Türk Edebiyatı Üzerine Araştırmalar, İstanbul: Dergâh.

Karataş, Turan (2004). Edebiyat Terimleri Sözlüğü, Ankara: Akçağ.

Moran, Berna (2001). Türk Romanı Eleştirel Bir Bakış-1, İstanbul: İletişim.

Moran, Berna (2011). Türk Romanı Eleştirel Bir Bakış-2, İstanbul: İletişim.

Okay, Orhan. (2005). Batılılaşma Devri Türk Edebiyatı, İstanbul: Dergâh.

Özön, Mustafa Nihat. (2009). Türkçede Roman, İstanbul: İletişim.

Tanpınar, Ahmet Hamdi. (2003). 19. Asır Türk Edebiyatı Tarihi, İstanbul: Çağlayan

Tekin, Arslan. (2010). Edebiyatımızda İsimler ve Terimler, İstanbul: Bilgeoğuz.

Uygur, Nermi (1977). İnsan Açısından Edebiyat, İstanbul: Edebiyat Fakültesi Basımevi 